\title{
Fractional Flow Reserve in Japanese Routine Clinical Practice
}

\author{
Hitoshi Matsuo, MD, PhD; Junko Honye, MD, PhD
}

$\mathbf{I}$ $\mathrm{t}$ is generally accepted that a stenosis with an ischemic value for fractional flow reserve (FFR) is responsible for symptoms and a worse outcome and should be revascularized, whereas lesions with a non-ischemic FFR value have a more favorable prognosis and can be treated medically. ${ }^{1-3}$ Furthermore, a FFR-guided revascularization strategy has been definitely proven to be better than an angiography-guided strategy in pivotal landmark studies. ${ }^{4}$ Based on these backgrounds, clinical guidelines from Europe and the USA strongly recommend the use of FFR assessment in routine clinical practice.

Therefore, it is surprising that the Japanese guideline currently does not include a statement regarding FFR. Looking at the specifics of Japanese interventional cardiology, we can find several differences from practice abroad. ${ }^{5}$ More than 250,000 procedures in $>800$ hospitals were performed in 2014 , which is estimated to be $>14$-fold of coro-

Article p1301

nary artery bypass grafting (CABG) procedures. Another distinct point is the high penetration of intravascular ultrasound (IVUS)-guided percutaneous coronary intervention (PCI) in Japan: $83 \%$ of the total PCI procedures performed in 2016 from the data of JROAD. This is a big advantage of Japanese-style intervention, because intravascular imaging has recently emerged as a critical modality for achieving better results of stent/scaffold implantation and superior clinical outcomes compared with coronary angiography alone. ${ }^{6}$

The proportion of elective procedures is $<40 \%$ of all PCI in the USA, but as many as three-quarters of PCI procedures are performed in the nonacute setting in Japan. Similar to the results in the USA, PCI is generally per-
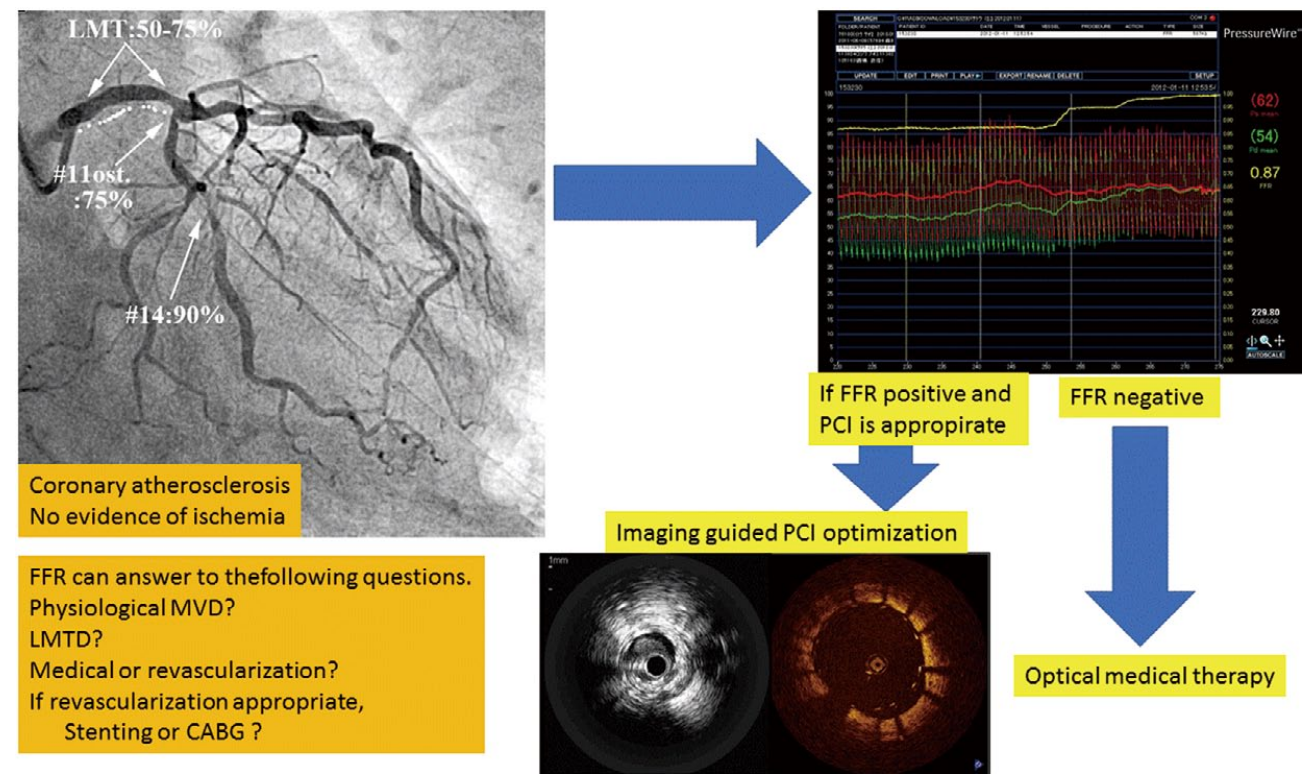

Figure. Incorporation of fractional flow reserve (FFR) measurement into clinical routine practice in Japan. CABG, coronary artery bypass grafting; LMTD, left main trunk disease; MVD, multivessel disease; $\mathrm{PCl}$, percutaneous coronary intervention.

The opinions expressed in this article are not necessarily those of the editors or of the Japanese Circulation Society.

Received July 24, 2017; accepted July 25, 2017; released online August 4, 2017

Department of Cardiovascular Medicine, Gifu Heart Center, Gifu (H.M.); Department of Cardiovascular Medicine, Kikuna Memorial Hospital, Kanagawa (J.H.), Japan

Mailing address: Hitoshi Matsuo, MD, PhD, Department of Cardiovascular Medicine, Gifu Heart Center, 4-14-4 Yabuta-Minami, Gifu 500-8384, Japan. E-mail: matsuo@heart-center.or.jp

ISSN-1346-9843 All rights are reserved to the Japanese Circulation Society. For permissions, please e-mail: cj@j-circ.or.jp 
formed appropriately in acute settings, but in non-acute settings, $15 \%$ of PCI cases were classified as inappropriate under the 2009 Appropriate Use Criteria (AUC), and $30.7 \%$ of PCI cases were categorized as inappropriate under the revised 2012 AUC. Because the infrastructure around the methods of ischemia detection differ greatly between Japan and other countries, the role and position of each modality, including FFR measurement, should be clarified under Japanese conditions.

Therefore, the CVIT DEFER registry is very important and contains valuable data for clarifying Japanese realworld practice of FFR measurement under the applicable condition of IVUS-guided PCI.

Briefly, the CVIT DEFER registry is a prospective multicenter registry enrolling 3,857 lesions from 3,272 consecutive patients with angiographically intermediate stenosis for whom FFR measurement was clinically indicated. This registry was undertaken to survey the current situation of FFR. Previous reports analyzing the CVIT DEFER registry have demonstrated the prevalence of visual-functional mismatch regarding coronary artery stenosis, with consequent high frequencies of modifying the treatment strategy, compared with the angiography-guided strategy.7,8 Angiographic FFR "mismatch", defined as visual stenosis $\geq 75 \%$ with FFR $>0.80$, was found in $43.4 \%$ of lesions, while reverse angiographic mismatch (visual stenosis $<75 \%$ with FFR $\leq 0.8$ ) was found in $23.2 \% .^{7}$ The independent predictors for "angiographic FFR mismatch", were the presence of PCI history, 1-vessel disease, non-left anterior descending artery (LAD) location, non-diffuse lesion, non-ostial lesion, and non-tandem lesion. Conversely, "reverse angiographic mismatch" was independently associated with multivessel disease, LAD location, and diffuse lesion. As for the treatment decision, the treatment strategy based on angiographic findings was medical management in $34.5 \%$, PCI in $63.5 \%$, and CABG in $2.1 \%$. The FFR in this population was found to be $<0.8$ in 1566 lesions $(42.2 \%)$. After FFR measurement, medical treatment was changed to revascularization in $19.7 \%$, while PCI was switched to medical treatment in $57.4 \%$ at the lesion level. As a result, reclassification of the treatment strategy at the patient level was done in $39.0 \%$ of the patients. ${ }^{8}$ Revascularization was frequently switched to medical treatment after FFR measurement.

In this issue of the Journal, Tanaka et $\mathrm{al}^{\mathbf{9}}$ present 1-year clinical outcomes from the CVIT-DEFER registry. The data show several important clinical points. First, the event rate of deferred lesions based on FFR (3.1\%/year) was significantly lower than that of events occurring in FFRnegative lesions treated by PCI (4.7\%/year). Secondly, there was a significant negative correlation between the event rate of deferred lesions and the FFR value, which clearly demonstrates FFR as a continuous risk marker rather than a dichotomized index. This result is similar to the results of a reviewed analysis ${ }^{\mathbf{1 0}}$ and a recently published
Korean IRIS registry, ${ }^{\mathbf{1 1}}$ where practice is very similar to Japanese style. The IRIS registry data clearly showed revascularization for coronary artery stenosis with a low FFR $(\leq 0.75)$ was associated with better outcomes than deferral, whereas for a stenosis with a high FFR $(\geq 0.76)$, medical treatment would be a reasonable and safe treatment strategy. All of these findings derived from the CVIT-DEFER registry, as well as the evidence from other countries, reconfirm the concept that the use of FFR and treatment decision making based on FFR in routine Japanese clinical practice leads to better prognosis of patients with ischemic heart disease. As shown in the Figure, FFR can answer the following questions. (1) Which lesion is responsible for the ischemia symptoms? (2) Is this patient suffered from physiological multivessel disease? (3) What kind of revascularization strategy is best for this patient: CABG or stenting? (4) Which vessel or which stenosed segment should be revascularized? After resolving these questions, imaging-guided PCI optimization should be the best way to improve prognosis for patients.

\section{References}

1. Pijls NHJ. Fractional flow reserve to guide coronary revascularization. Circ J 2013; 77: 561-569.

2. Nijjer SS, Sen S, Petraco R, Davies JE. Advances in coronary physiology. Circ J 2015; 79: 1172-1184.

3. Matsuo H, Kawase Y. FFR and iFR guided percutaneous coronary intervention. Cardiovasc Interv Ther 2016; 31: 183-195.

4. De Bruyne B, Fearon WF, Pijls NH, Barbato E, Tonino P, Piroth Z, et al. Fractional flow reserve-guided PCI for stable coronary artery disease. $N$ Engl J Med 2014; 371: 1208-1217.

5. Inohara T, Kohsaka S, Ueda I, Yagi T, Numasawa Y, Suzuki M, et al. Application of appropriate use criteria for percutaneous coronary intervention in Japan. World J Cardiol 2016; 8: $456-$ 463.

6. Hibi K, Kimura K, Umemura S. Clinical utility and significance of intravascular ultrasound and optical coherence tomography in guiding percutaneous coronary interventions. Circ J 2015; 79: $24-33$.

7. Nakamura M, Yamagishi M, Ueno T, Hara K, Ishiwata S, Itoh $\mathrm{T}$, et al. Prevalence of visual-functional mismatch regarding coronary artery stenosis in the CVIT-DEFER registry. Cardiovasc Interv Ther 2014; 29: 300-308.

8. Nakamura M, Yamagishi M, Ueno T, Hara K, Ishiwata S, Itoh $\mathrm{T}$, et al. Modification of treatment strategy after FFR measurement: CVIT-DEFER registry. Cardiovasc Interv Ther 2015; 30: $12-21$.

9. Tanaka N, Nakamura M, Akasaka T, Kadota K, Uemura S, Amano T, et al; for the CVIT-DEFER Registry Investigators. One-year outcome of fractional flow reserve-based coronary intervention in Japanese daily practice: CVIT-DEFER Registry. Circ J 2017; 81: 1301-1306.

10. Johnson NP, Toth GG, Lai D, Zhu H, Acar G, Agostoni P, et al. Prognostic value of fractional flow reserve: Linking physiologic severity to clinical outcomes. J Am Coll Cardiol 2014; 64: $1641-1654$

11. Ahn JM, Park DW, Shin ES, Koo BK, Nam CW, Doh JH, et al. Fractional flow reserve and cardiac events in coronary artery disease: Data From a Prospective IRIS-FFR Registry (Interventional Cardiology Research Incooperation Society Fractional Flow Reserve). Circulation 2017; 135: 2241-2251. 